\title{
Strategic influence on the time course of predictive inferences in reading
}

\author{
MANUEL G. CALVO and M. DOLORES CASTILLO \\ University of La Laguna, Tenerife, Spain \\ and \\ FRANZ SCHMALHOFER \\ University of Osnabrück, Osnabrück, Germany
}

\begin{abstract}
In the present study, we investigated how reading strategies affect the time course of online predictive inferences. Participants read sentences under instructions either to anticipate the outcomes of described events or to understand the sentences. These were followed by a target word to be named, with stimulus onset asynchronies (SOAs) of 500 or 1,000 msec (50- or 550-msec interstimulus interval, respectively). Sentences either were predictive of events or were lexically matched control sentences. There was facilitation in naming latencies for predictable target words in the strategic-anticipation condition at both SOAs, but not in the read-to-understand condition, with a significant improvement in the former condition in comparison with the latter. This suggests that predictive inferences, which are typically considered to be resource demanding, can be speeded up by specific goals in reading. Moreover, this can occur at no cost to comprehension of explicit information, as was revealed by a comprehension test.
\end{abstract}

Reading comprehension involves both extracting meaning from explicit text and constructing inferences by integrating text information with the reader's prior knowledge. Inferences can be mainly text based and serve to connect different parts of the message, thus making a passage coherent, or they can be mainly knowledge based and serve to elaborate and expand the explicitly stated information. This is a necessary process for constructing a situation model of what the text describes (Zwaan \& Radvansky, 1998). Predictive inferences are one type of knowledgebased inference that has received considerable attention (see, e.g., Calvo, Castillo, \& Estevez, 1999; Cook, Limber, \& O'Brien, 2001; Fincher-Kiefer, 1996; Keefe \& McDaniel, 1993; Klin, Guzmán, \& Levine, 1999; McKoon \& Ratcliff, 1986; Peracchi \& O’Brien, 2004; Schmalhofer, McDaniel, \& Keefe, 2002; Weingartner, Guzmán, Levine, \& Klin, 2003). These inferences represent the likely outcome(s) of a described situation or event, such as anticipating that the vase broke when reading the sentence The delicate porcelain vase was thrown against the wall (see, e.g., Potts, Keenan, \& Golding, 1988).

Models of inference processing, such as the minimalist hypothesis (McKoon \& Ratcliff, 1992) and the constructionist theory (Graesser, Singer, \& Trabasso, 1994), have proposed that predictive inferences will be drawn online

This research was supported by Grant BSO2001-3753 from the Dirección General de Investigación, Ministerio Español de Ciencia y Tecnología. Correspondence concerning this article should be addressed to M. G. Calvo, Department of Cognitive Psychology, University of La Laguna, 38205 Tenerife, Spain (e-mail: mgcalvo@ull.es). only when they are highly constrained by the context of the message, with few alternative outcomes to anticipate, and when the respective knowledge is readily available from long-term memory or currently activated in working memory. Furthermore, these inferences would not be automatic; rather, they involve postlexical elaborative processes and take time to be constructed. Prior research has found evidence of online predictive inferences during reading, when the conditions of context constraints and readiness in the availability of knowledge have been met (Calvo, 2000; Calvo \& Castillo, 1998; Cook et al., 2001; Fincher-Kiefer, 1995, 1996; Keefe \& McDaniel, 1993; Klin, Guzmán, \& Levine, 1999; Klin, Murray, Levine, \& Guzmán, 1999; Murray, Klin, \& Myers, 1993; Weingartner et al., 2003; Whitney, Ritchie, \& Crane, 1992). This is demonstrated by facilitation in the processing (e.g., naming, reading, lexical decision times) of a probe or target word that represents the inference concept following the inducing context, relative to a control context. However, there have also been results showing no evidence of predictive inferences (Magliano, Baggett, Johnson, \& Graesser, 1993; Millis \& Graesser, 1994; Potts et al., 1988) and findings suggesting that predictive inferences are made only minimally or partially (Duffy, 1986; McKoon \& Ratcliff, 1986).

These inferences have been found to take time to construct and to occur with delay. This evidence comes mainly from studies in which the manipulation of stimulus onset asynchrony (SOA - i.e., the interval between the onset of the last context word and the onset of the target word) was combined with word-by-word, fixed-pace, rapid serial visual presentation (RSVP) of the context sentence. Calvo and Castillo (1996, 1998, 2001) and Calvo et al. (1999) 
observed facilitation in naming the inferential target word under 1,250- and 1,500-msec SOA conditions, but not when 500- or 1,000-msec SOAs were used. Only with enhanced context constraints could predictive inferences be speeded up to some extent (i.e., in a 1,000-msec but not in a 500-msec SOA condition; Calvo, 2000). Fincher-Kiefer $(1995,1996)$ also obtained evidence with a single 1,000msec SOA. In contrast, neither Magliano et al. (1993) nor Millis and Graesser (1994) detected predictive inferences with SOAs ranging from 250 to $1,200 \mathrm{msec}$. This implies that if these inferences are to be made online, they need about $1 \mathrm{sec}$ after the end of the inducing context.

It could, however, be argued that the fixed-pace, oneword-at-a-time reading procedure does not represent natural reading. Therefore, in other studies, self-paced reading and the presentation of one sentence or one line at a time have been used. After a short, blank interstimulus interval (ISI; 250-1,500 msec), the inference probe word appears (Campion \& Rossi, 2001; Cook et al., 2001; Keefe \& McDaniel, 1993; Klin, Guzmán, \& Levine, 1999; Klin, Murray, et al., 1999; McDaniel, Schmalhofer, \& Keefe, 2001; Peracchi \& O’Brien, 2004; Weingartner et al., 2003; Whitney et al., 1992). The fact that inferences were detected after such short intervals suggests that they can occur with only a minimal delay. Nevertheless, with this procedure the time course cannot be determined with precision: The reason is that the participants can decide when to finish reading the context sentence, which implies that they actually have all the time they need to draw the inference before the context-probe interval. In an alternative self-paced procedure, reading times are collected during the presentation of the context sentence and a continuation sentence that contains the inferential word. Calvo and Castillo (1998) and Calvo, Meseguer, and Carreiras (2001) used this procedure, with a moving-window technique and with eye-movement assessment, respectively. With these paradigms, facilitation did not occur in reading the target word itself but rather in the posttarget and final regions of the continuation sentence (Calvo \& Castillo, 1998). Furthermore, facilitation was not observed in early processing measures, such as first-fixation duration or first-pass reading time of the target word, but rather in late-processing measures, such as regressive fixations to the target word and second-pass reading time (Calvo et al., 2001).

Accordingly, the results of studies using the SOA and RSVP paradigms and those using self-paced procedures converge in showing that predictive inferences need time to be constructed. Presumably, predictive inferences are drawn or completed with delay because of the demands of the cognitive processes involved and the nature of the inferential representation. Thus, according to the construction-integration (C-I) model (Kintsch, 1988, 1998; see Schmalhofer et al., 2002; see also Lea, Kayser, Mulligan, \& Myers, 2002), initially, in the construction phase, multiple knowledge units or nodes are automatically activated during lexical access to the word meanings. This provides the basic material for the inferences to be constructed later, but it can produce a large amount of information. At this point, selection processes must constrain the most appropriate interpretation, according to the prior context and knowledge. This selection process would also be applied to predictive inferences. The reason is that these are probabilistic rather than logical or necessary inferences. Therefore, multiple alternative inferences could be generated and one of them should be preferentially selected for the integration phase. In the integration phase, the predictive inference would become a part of the situation model (McDaniel et al., 2001). Nevertheless, at this level of representation the predictive inference is probably of a descriptive rather than an abstract or linguistic nature. That is, the inference would depict specific aspects of actions or events, even at a sensorimotor or mental-imagery level, with minimal conceptualization and verbalization. In order for this situation model representation to facilitate the processing (e.g., lexical decision, naming, reading) of a probe word, the inference must be coded into a linguistic format, given that the to-be-matched probe is verbal (Calvo, 2000). All these processes would explain why predictive inferences need time to be constructed and are, therefore, detected with delay.

The purpose of the present study is to determine whether the time course of predictive inferences can be strategically shortened by means of orienting instructions aimed at active predicting during reading. According to the foregoing analysis, the time course of these inferences should not be susceptible to being shortened by strategic orienting during reading. There are, however, some data showing that at least the probability and durability of these inferences can be increased by means of strategic reading (Magliano, Trabasso, \& Graesser, 1999; Trabasso \& Magliano, 1996; van den Broek, Lorch, Linderholm, \& Gustafson, 2001). Thus, when readers are instructed to predict what can happen next, it has been found that predictive inferences are specifically produced under the prediction-oriented conditions rather than under other reading conditions, as is revealed by think-aloud protocols (Magliano et al., 1999). Moreover, when readers are instructed to predict events, reading times have been found to decrease for sentences that confirmed the predictions (Magliano et al., 1999). Another support for the assumption that predictive inferences can be strategically induced and maintained online comes from McDaniel et al.'s (2001) study. These authors asked participants to focus either on the situation described by the inducing sentences or on the wording of the sentences. Inferences were more durable over a consecutive sentence in the former condition than over one in the latter condition, as is revealed by shorter naming latencies for inferential probe words.

The critical issue to be addressed now is whether a strategic approach during reading can also affect the time course of predictive inferences (not only the probability that they will reach a certain activation level). To examine this issue in the present study, we first presented context sentences that either predicted (predicting context) or did not predict (control context) a likely event (see Table 1). 
Table 1

Experiments 1-3: Sample Corpus Materials for the Predicting and Control Context Passages, the Inferential and Nonpredictable Target Words, and the Probes to Assess Comprehension of Explicit Information

\begin{tabular}{|c|c|}
\hline Material & Example \\
\hline Predicting context sentence & $\begin{array}{l}\text { At the restaurant with some friends he had } \\
\text { invited, when dinner was finished, Harry asked } \\
\text { the waiter to bring him the check and got out } \\
\text { his wallet. } \\
\text { Experiments } 1 \text { and } 2 \text { : Harry }{ }^{* *} \text { TARGET WORD } \\
\text { Experiment } 3:{ }^{* *} \text { TARGET WORD }{ }^{* *}\end{array}$ \\
\hline Control context sentence & $\begin{array}{l}\text { After having had dinner with some friends he } \\
\text { had invited, Harry called the restaurant to ask } \\
\text { the waiter to check if he had left his wallet. } \\
\text { Experiments } 1 \text { and } 2 \text { : Harry }{ }^{* *} \text { TARGET WORD } \\
\text { Experiment } 3:{ }^{* *} \text { TARGET WORD }\end{array}$ \\
\hline Inferential & ${ }^{* *}$ paid ${ }^{* *}$ \\
\hline Nonpredicta & ${ }^{* *}$ smiled ${ }^{* *}$ \\
\hline Comprehension probe & $\begin{array}{l}\text { Harry had dinner with some friends at a } \\
\text { restaurant. (true) } \\
\text { Harry had dinner with some colleagues at a } \\
\text { restaurant. (false) }\end{array}$ \\
\hline
\end{tabular}

Note- Context and target were combined, so that on each trial only one context sentence (either predicting or control) and one target word (either inferential or nonpredictable) were presented, along with only one comprehension probe (either true or false). In the experiments, all materials were presented in Spanish.

These sentences were followed by a target word to be named, which represented either the predictable event (inferential word) or an unlikely event (nonpredictable word). We expected facilitation (i.e., shorter latencies) in naming a given inferential word following the predicting context than following the control context. In contrast, no difference between contexts was expected for the nonpredictable target words. Second, we had one group of participants perform the reading and naming tasks following strategic orienting instructions (these participants were asked to actively anticipate likely outcomes of the described events in each sentence), whereas participants in the nonorienting condition were asked only to understand the sentences. Third, we varied the SOA between the last word of the context sentence (i.e., the pretarget word) and the target word to be named. This SOA was either 500 or $1,000 \mathrm{msec}$. If strategic processing shortens the time course of inferences, then facilitation in naming will be greater at 500- and/or 1,000-msec SOAs in the strategic orienting condition than in the nonorienting condition.

\section{EXPERIMENT 1}

\section{Method}

Participants. Ninety-six Spanish psychology undergraduates participated for course credit. The mean age of the participants in the orienting condition was 19.6 years, and that in the nonorienting condition was 19.7 years. There were 11 males and 37 females in each condition.

Materials. We used 40 corpora of materials, most of which were Spanish adaptations of the original English sentences used by McKoon and Ratcliff (1986), Keefe and McDaniel (1993), and many other researchers (see Calvo \& Castillo, 1998; Calvo et al., 1999). Each corpus (see Table 1 for an example) was composed of one predicting context sentence, one control context sentence, one inferential target word, and one nonpredictable target word. Four passages were constructed from each corpus by combining context sentences with targets. Each participant received one passage from each corpus, in 40 trials in random order, and saw a particular context and target only once. On each trial, each participant was presented with either a predicting or a control sentence followed by either an inferential or a nonpredictable target word.

Before the experiments, we assessed the validity of the materials in a number of ways (see Calvo, 2000; Calvo et al., 1999). Initially, we controlled word-based priming - that is, activation of the target word due to semantic associations with individual words in the context (Keenan, Golding, Potts, Jennings, \& Aman, 1990). We identified words in each predicting context that could have any relationship with the target word. These words were included in the respective control contexts. Subsequently, using a sentence completion procedure (see, e.g., Magliano et al., 1993), we asked a different group of participants to read the passages, predict what could happen next, and write the first word that came to mind. The oneword predictions served as targets. Two targets (one inferential and one nonpredictable) were selected for each context. The former was mentioned by $82 \%$ of the participants after the predicting context and by $8 \%$ after the control context; for the latter, the respective scores were $2 \%$ and $3 \%$. Finally, we made sure that the predicting and control contexts were equivalent in length (both $M \mathrm{~s}=20.6$ words). In addition, the inferential target words did not differ from the nonpredictable words in number of characters $(M=6.64 \mathrm{vs}$. $M=6.67$, respectively) or word frequency ( $M=33.2 /$ million vs. $M=35.4$ /million, respectively; Alameda \& Cuetos, 1995).

Design. A 2 (priming context: predicting vs. control) $\times 2$ (target word: inferential vs. nonpredictable) $\times 2$ (SOA: 500 vs. $1,000 \mathrm{msec}) \times$ 2 (orienting instructions: strategic vs. nonorienting) factorial design was used. Context and target were within-subjects factors, and orienting and SOA were between-subjects factors. Forty-eight participants were randomly assigned to each orienting condition, with 24 participants at each SOA.

In the predicting condition, the context sentence suggested a likely event. In the control condition, the sentence was not predic- 
tive of any particular event. The inferential word represented the predictable event. The nonpredictable word represented a plausible but unlikely event.

In the 500-msec SOA condition, the interval between the onset of the pretarget word and the onset of the target word was $500 \mathrm{msec}$, which represented a 50-msec blank ISI between the offset of the pretarget word and the onset of the target word (since the presentation of the pretarget word always lasted for $450 \mathrm{msec}$ ). In the 1,000-msec SOA condition, the pretarget-target onset asynchrony was $1,000 \mathrm{msec}$, which represented a 550-msec ISI. The manipulation of the SOA between the last context word (pretarget) and the probe word, along with the fixed-pace, word-by-word presentation, was used to assess the time course of predictive inferences. It must, however, be noted that the true SOA between the inference-promoting words in the context sentence and the target word is difficult to quantify. The reason is that, unlike the activation of lexical associates by single words, the generation of elaborative inferences involves postlexical processes following the combination of meanings from several words in a sentence (see, e.g., Long, Oppy, \& Seely, 1994; Till, Mross, \& Kintsch, 1988). Nevertheless, although the inference process can start earlier during sentence reading (with a vague or minimal meaning), the completion of the inference (with a more specific meaning, which can be verbalized) is assumed to be deferred until an integration or wrap-up stage at the end of the sentence (Calvo et al., 1999; Kintsch, 1988). This is why it makes sense to manipulate the SOA between the last context sentence word and the probe word.

Regarding orienting instructions, in the strategic condition the participants were asked to read for comprehension of each sentence and, in addition, to predict or try to anticipate what could happen next while they were reading silently. More specifically, they were requested to "think about the likely consequences of the events, actions, and states occurring in the situations described in each sentence," in accordance with the instructions used by Magliano et al. (1999). In the nonorienting condition, the participants were asked only to read for comprehension of the sentences. It should be noted that, for each participant, only $25 \%$ of the trials (predicting + inferential) induced inferences, whereas $50 \%$ (controls) were neutral and $25 \%$ (predicting + nonpredictable) clearly discouraged such inferential activity. In these conditions, it is not likely that the participants consciously made inferences as a strategy for meeting the demands of the experiment, unless required to do so (i.e., in the strategic orienting condition).

Procedure. Stimulus presentation on a screen and response collection were controlled by PCs. Each word was exposed for $300 \mathrm{msec}$ plus $25 \mathrm{msec}$ per letter, and there was a 50 -msec interval between words. The estimated mean word exposure across a sentence was $418 \mathrm{msec}$. The pretarget word (e.g., Harry) was always presented for $450 \mathrm{msec}$. Each trial began when the participant pressed the space bar. Five hundred milliseconds later, the words of the context appeared and disappeared one at a time in the center of the screen. After the corresponding SOA at the end of the context, the target word appeared flanked by asterisks (e.g., ** paid **). The participants were told to say the target words correctly as quickly as possible. A microphone connected to a voice-activated relay and interfaced with the computer registered the accuracy and latency of the naming responses.

A comprehension probe was presented after the word naming at the end of each trial (see Table 1 for an example). The participants responded by pressing one of two keys ("Yes" and "No"). We included this test to encourage the participants to read for comprehension of the sentences, and also to have a measure of their comprehension of explicit information. This was useful for examining whether or not the adoption of the predicting strategy to infer implicit content could draw processing resources to such an extent that it was detrimental to the comprehension of explicit information in the orienting condition.

\section{Results}

Naming accuracy and latencies. For this and the following experiments, pronunciation errors $(<2 \%)$ did not vary as a function of experimental condition. Naming latencies above or below $2.5 \mathrm{SDs}$ from the mean $(<4 \%)$ were replaced by the participant's mean score $\pm 2.5 \mathrm{SDs}$ in each condition.

We conducted a 2 (context) $\times 2$ (target) $\times 2($ SOA $) \times$ 2 (orienting) ANOVA on both subject $\left(F_{1}\right)$ and item $\left(F_{2}\right)$ mean correct naming latencies (see Table 2 ). The criterion for determining the activation of an inference concept is facilitation (i.e., shorter latencies) in naming an inferential target word following the predicting context relative to the control context. Accordingly, whenever interactions between context and the other factors emerged, planned contrasts between the predicting and the control contexts were performed for each orienting condition and each SOA condition.

Main effects of SOA, context, and target revealed that naming times were $55 \mathrm{msec}$ shorter for the 1,000- than for the 500-msec SOA condition $\left[F_{1}(1,94)=11.94, M S_{\mathrm{e}}=\right.$ $49,890, p<.001 ; F_{2}(1,156)=119.19, M S_{\mathrm{e}}=4,211, p<$ $.0001]$. They were $17 \mathrm{msec}$ shorter following the predicting context than following the control context $\left[F_{1}(1,94)=\right.$ $22.40, M S_{\mathrm{e}}=2,274, p<.0001 ; F_{2}(1,156)=10.23$, $\left.M S_{\mathrm{e}}=3,663, p<.01\right]$ and $33 \mathrm{msec}$ shorter for the inferential than for the nonpredictable target words $\left[F_{1}(1,94)=\right.$ $120.16, M S_{\mathrm{e}}=1,667, p<.0001 ; F_{2}(1,156)=22.10$, $\left.M S_{\mathrm{e}}=7,998, p<.0001\right]$. However, these effects were qualified by a context $\times$ target interaction $\left[F_{1}(1,94)=\right.$

Table 2

Mean Naming Latencies (in Milliseconds) for the Inferential and Nonpredictable Target Words Following the Predicting and Control Contexts, at 500- and 1,000msec SOAs, Under the Strategic Orienting and Nonorienting Conditions of Experiment 1

\begin{tabular}{|c|c|c|c|c|c|c|c|c|c|}
\hline \multirow[b]{3}{*}{ SOA } & \multirow[b]{3}{*}{ Target } & \multicolumn{4}{|c|}{$\begin{array}{l}\text { Strategic Orienting } \\
\text { Reading Context }\end{array}$} & \multicolumn{4}{|c|}{$\begin{array}{c}\text { Nonorienting Reading } \\
\text { Context }\end{array}$} \\
\hline & & \multicolumn{2}{|c|}{ Predicting } & \multicolumn{2}{|c|}{ Control } & \multicolumn{2}{|c|}{ Predicting } & \multicolumn{2}{|c|}{ Control } \\
\hline & & $M$ & $\overline{S D}$ & $M$ & $\overline{S D}$ & $M$ & $\overline{S D}$ & $M$ & $S D$ \\
\hline \multirow[t]{2}{*}{$500 \mathrm{msec}$} & inferential & 634 & 109 & 690 & 126 & 670 & 99 & 667 & 105 \\
\hline & nonpredictable & 687 & 139 & 708 & 134 & 694 & 117 & 685 & 133 \\
\hline \multirow[t]{2}{*}{$1,000 \mathrm{msec}$} & inferential & 563 & 87 & 607 & 116 & 618 & 97 & 636 & 111 \\
\hline & nonpredictable & 633 & 115 & 630 & 113 & 650 & 107 & 654 & 133 \\
\hline
\end{tabular}


$10.88, M S_{\mathrm{e}}=2,886, p<.01 ; F_{2}(1,156)=6.41, M S_{\mathrm{e}}=$ $3,663, p<.025$ ] and further by a three-way (orienting $\times$ context $\times$ target $)$ interaction $\left[F_{1}(1,94)=4.11, M S_{\mathrm{e}}=\right.$ $2,886, p<.05 ; F_{2}(1,156)=3.93, M S_{\mathrm{e}}=3,663, p<$ .05]. The four-way interaction was not significant (both $\left.F_{\mathrm{S}}<1\right)$. An interesting additional effect indicated that there was an increase in facilitation for the predictable targets from the nonorienting condition to the orienting condition $\left[F_{1}(1,94)=20.22, M S_{\mathrm{e}}=2,257, p<.0001\right.$; $\left.F_{2}(1,158)=8.88, M S_{\mathrm{e}}=3,857, p<.01\right]$.

In order to decompose the three-way interaction, we analyzed each orienting condition separately. In the strategic condition, in addition to the main effects of SOA, context, and target (defined as in the overall analyses - see above), the important finding was a context $\times$ target interaction $\left[F_{1}(1,47)=12.40, M S_{\mathrm{e}}=3,302, p<.001 ; F_{2}(1,78)=\right.$ 12.52, $\left.M S_{\mathrm{e}}=2,982, p<.001\right]$. Separate ANOVAs for each SOA condition confirmed that the context $X$ target interaction was significant in both the 500-msec $\left[F_{1}(1,47)=4.97, M S_{\mathrm{e}}=3,098, p<.05 ; F_{2}(1,78)=4.07\right.$, $\left.M S_{\mathrm{e}}=3,603, p<.05\right]$ and $1,000-\operatorname{msec}\left[F_{1}(1,47)=\right.$ $13.11, M S_{\mathrm{e}}=2,004, p<.001 ; F_{2}(1,78)=7.73, M S_{\mathrm{e}}=$ 2,993, $p<.001]$ SOA conditions. The three-way interaction was not significant (both $F_{\mathrm{S}}<1$ ). Across SOAs, planned comparisons indicated that for the inferential words naming latencies were $50 \mathrm{msec}$ shorter following the predicting context than following the control context $\left[F_{1}(1,47)=66.71, M S_{\mathrm{e}}=1,863, p<.0001 ; F_{2}(1,78)=\right.$ $\left.35.63, M S_{\mathrm{e}}=2,982, p<.0001\right]$. In contrast, for the nonpredictable words there was no significant difference $\left[9 \mathrm{msec} ; F_{1}(1,47)=1.53, M S_{\mathrm{e}}=2,865, p>.20 ; F_{2}<1\right]$. This implies that inferences were drawn in the strategic orienting condition.

In the nonorienting condition, the only main effects that emerged were those of SOA and target (defined as in the overall analyses - see above). Naming times were $40 \mathrm{msec}$ shorter in the 1,000- than in the 500-msec SOA condition $\left[F_{1}(1,47)=3.30, M S_{\mathrm{e}}=46,054, p=.075 ; F_{2}(1,78)=\right.$ $\left.19.77, M S_{\mathrm{e}}=11,312, p<.0001\right]$ and $23 \mathrm{msec}$ shorter for the inferential than for the nonpredictable target words $\left[F_{1}(1,47)=27.62, M S_{\mathrm{e}}=1,826, p<.0001 ; F_{2}(1,78)=\right.$ $\left.4.02, M S_{\mathrm{e}}=11,312, p<.05\right]$. No other effects were significant, including the context $\times$ target interaction and the three-way interaction (all $F_{\mathrm{S}}<1$ ).

Comprehension performance. A 2 (context) $\times$ 2 (SOA) $\times 2$ (orienting) ANOVA was applied to mean scores of comprehension performance for explicit information in the context sentences, with no statistically significant effects. Particularly, the effect of strategic orienting was not significant $(F<1)$ : The participants responded correctly to $88.8 \%$ and $87.4 \%$ of the questions in the strategic orienting condition and the nonorienting condition, respectively. The means for the 500- and 1,000-msec SOA conditions were $88.3 \%$ and $87.9 \%$, respectively (both $F_{\mathrm{s}}<1$ ).

\section{Discussion}

As is shown by the facilitation in naming of predictable target words following the predicting context (in comparison with the control context), the results revealed inference activation at both SOAs in the strategic orienting condition but at neither SOA in the nonorienting condition, with a significant increase in activation in the strategic condition in comparison with the nonorienting condition. Furthermore, as is indicated by the lack of effects of strategic orienting on comprehension of explicit text, the enhanced inferential activity in the orienting condition occurred at no cost to comprehension of the information provided in the sentences and was not due to a general improvement in comprehension.

A major contribution of this study is that not only can the probability of predictive inferences be increased by strategic reading aimed at anticipating probable outcomes of events described in sentences (Magliano et al., 1999; McDaniel et al., 2001; Trabasso \& Magliano, 1996; van den Broek et al., 2001), but the time course of these inferences is also affected. There are, however, two issues to be addressed in order to further examine this effect. First, there is the question of whether the influence of strategic reading on the time course of predictive inferences depends on the amount of time available for reading the sentence in comparison with the amount of time following the end of the sentence (i.e., the during-context vs. postcontext processing time; Calvo et al., 1999). Second, there is the question of whether strategic reading affects the initial computation of the inference while the sentence is being read, or whether this effect takes place upon reactivation of the inference following the sentence, when the pretarget word appears. To investigate each of these two issues, Experiments 2 and 3, respectively, were conducted. Since both issues are related and relevant to the time course of predictive inferences - that is, to when the inference is drawn under strategic reading conditionsExperiments 2 and 3 will be reported together.

\section{EXPERIMENTS 2 AND 3}

In Experiment 2, we used a higher presentation rate than in Experiment 1 for the words of the context sentences. If the shortened time course under strategically oriented reading depends on the time available for reading the sentence, then the facilitation effects will no longer be significant when the available reading time is shortened by a higher presentation rate. In Experiment 3, unlike in Experiments 1 and 2, the target word was presented immediately after the last word of the context, with no reactivating pretarget word between them (see Table 1). If the shortened time course depends on the presence of a postcontext reactivating cue, the facilitation effects will disappear when that cue is removed following the end of the context sentence. 


\section{Method}

Participants. Forty-eight Spanish psychology undergraduates (38 females; mean age, 19.9 years) participated for course credit in Experiment 2, and another 48 (38 females; mean age, 19.7 years) participated in Experiment 3. All belonged to the same pool of firstyear students and were randomly assigned to either Experiment 2 or Experiment 3.

Materials. For Experiment 2, the same corpora of materials were used as in Experiment 1. For Experiment 3, a change was made in the materials: We removed the postcontext pretarget word (i.e., Harry in the example presented in Table 1), which always referred to the subject of the to-be-inferred action (represented by the inferential target word). Accordingly, as is indicated in Table 1, the target word appeared immediately after the last word of the context sentence (i.e., "wallet"), which then served as a pretarget word.

Design and Procedure. A 2 (priming context: predicting vs. control) $\times 2$ (target word: inferential vs. nonpredictable) $\times 2$ (SOA: 500 vs. $1,000 \mathrm{msec}$ ) factorial design was used for each experiment, with context and target as within-subjects factors and SOA as a between-subjects factor. Twenty-four participants were randomly assigned to each SOA level in each experiment.

In both Experiments 2 and 3, strategic orienting instructions were used. The procedure for Experiment 2 was the same as that for Experiment 1 , with the exception of a higher presentation rate for the words in the context sentence. The temporal parameters were reduced to $66.6 \%$ in comparison with the $100 \%$ rate of Experiment 1 . Thus, at the $66.6 \%$ rate, each word was exposed for $200 \mathrm{msec}$ plus $17 \mathrm{msec}$ per character, which yielded a mean word exposure of $279 \mathrm{msec}$ across an average sentence (plus a 50-msec blank interval between words). The procedure for Experiment 3 was the same as that for Experiment 1 (with a $100 \%$ presentation rate), except for the change regarding the removal of the pretarget cue word (see the Materials section, above). The word preceding the target word was always presented for $450 \mathrm{msec}$.

\section{Results}

Naming latencies. The subject $\left(F_{1}\right)$ and item $\left(F_{2}\right)$ mean correct naming latencies were subjected to 2 (context) $\times 2$ (target) $\times 2$ (SOA) ANOVAs (see Table 3 ) .

In Experiment 2, main effects of SOA, context, and target revealed that naming times were $56 \mathrm{msec}$ shorter for the 1,000-msec than for the 500-msec SOA condition $\left[F_{1}(1,47)=6.19, M S_{\mathrm{e}}=48,506, p<.025 ; F_{2}(1,78)=\right.$ $\left.58.15, M S_{\mathrm{e}}=4,328, p<.0001\right]$. They were $23 \mathrm{msec}$ shorter following the predicting context than following the control context $\left[F_{1}(1,47)=27.81, M S_{\mathrm{e}}=1,802, p<\right.$ $\left..0001 ; F_{2}(1,78)=12.76, M S_{\mathrm{e}}=3,236, p<.001\right]$ and $45 \mathrm{msec}$ shorter for the inferential than for the nonpredictable target words $\left[F_{1}(1,47)=102.09, M S_{\mathrm{e}}=1,895\right.$, $\left.p<.0001 ; F_{2}(1,78)=25.62, M S_{\mathrm{e}}=6,238, p<.0001\right]$.
These effects were qualified by a context $\times$ target interaction $\left[F_{1}(1,47)=8.79, M S_{\mathrm{e}}=3,095, p<.01 ; F_{2}(1,78)=\right.$ $\left.7.52, M S_{\mathrm{e}}=3,236, p<.01\right]$. The three-way interaction was not significant (both $F \mathrm{~s}<1$ ). Across SOA conditions, planned comparisons indicated that, for the inferential words, naming latencies were $40 \mathrm{msec}$ shorter following the predicting context than following the control context $\left[F_{1}(1,47)=50.32, M S_{\mathrm{e}}=1,502, p<.0001 ; F_{2}(1,78)=\right.$ $\left.19.94, M S_{\mathrm{e}}=3,236, p<.0001\right]$. For the nonpredictable words, there was no significant difference $(6 \mathrm{msec}$; both $\left.F_{\mathrm{S}}<1\right)$

In Experiment 3, main effects of SOA, context, and target revealed that naming times were $56 \mathrm{msec}$ shorter for the 1,000-msec than for the 500-msec SOA condition $\left[F_{1}(1,47)=5.82, M S_{\mathrm{e}}=51,636, p<.025 ; F_{2}(1,78)=\right.$ 62.08, $\left.M S_{\mathrm{e}}=4,055, p<.0001\right]$. They were $15 \mathrm{msec}$ shorter following the predicting context than following the control context $\left[F_{1}(1,47)=7.80, M S_{\mathrm{e}}=2,883\right.$, $\left.p<.01 ; F_{2}(1,78)=5.87, M S_{\mathrm{e}}=3,365, p<.025\right]$ and $37 \mathrm{msec}$ shorter for the inferential than for the nonpredictable target words $\left[F_{1}(1,47)=58.18, M S_{\mathrm{e}}=2,200\right.$, $\left.p<.0001 ; F_{2}(1,78)=17.82, M S_{\mathrm{e}}=5,884, p<.0001\right]$. These effects were qualified by a context $\times$ target interaction $\left[F_{1}(1,47)=9.91, M S_{\mathrm{e}}=3,466, p<.01 ; F_{2}(1,78)=\right.$ $\left.8.52, M S_{\mathrm{e}}=3,365, p<.01\right]$. The three-way interaction was not significant (both $F \mathrm{~s}<1$ ). Across SOA conditions, planned comparisons indicated that, for the inferential words, naming latencies were $34 \mathrm{msec}$ shorter following the predicting context than following the control context $\left[F_{1}(1,47)=18.16, M S_{\mathrm{e}}=3,095, p<.0001 ; F_{2}(1,78)=\right.$ 14.27, $\left.M S_{\mathrm{e}}=3,365, p<.001\right]$. For the nonpredictable words, there was no significant difference $(3 \mathrm{msec}$; both $F \mathrm{~s}<1)$.

Comprehension performance. A $2(\mathrm{SOA}) \times 2$ (context) ANOVA on comprehension scores for explicit information in the sentences yielded no significant effects. The means for the 500- and 1,000-msec SOA conditions were $85.5 \%$ and $85.7 \%$, respectively, in Experiment 2 and $87.7 \%$ and $88.1 \%$, respectively, in Experiment 3 .

\section{Discussion}

There was facilitation in naming the target words that represented the inference concept following the predicting context in both the 500- and 1,000-msec SOA conditions, with the higher presentation rate (Experiment 2) as well

Table 3

Mean Naming Latencies (in Milliseconds) for the Inferential and Nonpredictable Target Words Following the Predicting and Control Contexts, at 500- and 1,000msec SOAs, Under the Strategic Orienting Conditions of Experiments 2 (Higher Presentation Rate) and 3 (No Pretarget Cue Word)

\begin{tabular}{|c|c|c|c|c|c|c|c|c|c|}
\hline \multirow[b]{3}{*}{$\mathrm{SOA}$} & \multirow[b]{3}{*}{ Target } & \multicolumn{4}{|c|}{ Experiment 2} & \multicolumn{4}{|c|}{ Experiment 3} \\
\hline & & \multicolumn{2}{|c|}{ Predicting } & \multicolumn{2}{|c|}{ Control } & \multicolumn{2}{|c|}{ Predicting } & \multicolumn{2}{|c|}{ Control } \\
\hline & & $M$ & $\overline{S D}$ & $M$ & $\overline{S D}$ & $M$ & $\overline{S D}$ & $M$ & $\overline{S D}$ \\
\hline \multirow[t]{2}{*}{$500 \mathrm{msec}$} & inferential & 630 & 105 & 670 & 139 & 641 & 100 & 676 & 121 \\
\hline & nonpredictable & 688 & 115 & 699 & 125 & 694 & 125 & 695 & 12 \\
\hline \multirow[t]{2}{*}{$1,000 \mathrm{msec}$} & inferential & 573 & 88 & 613 & 114 & 585 & 108 & 619 & 122 \\
\hline & nonpredictable & 639 & 111 & 640 & 106 & 643 & 118 & 635 & 113 \\
\hline
\end{tabular}


as with no reactivating pretarget cue word (Experiment 3). This corroborates the results of Experiment 1 and demonstrates that strategic reading produces a genuine effect on the time course of inferences, overriding (1) reductions in the time needed to read the single words of context sentences (i.e., higher reading rate) and (2) reductions in the constraints with which the context induces the inference (i.e., removal of the pretarget cue word). Accordingly, the strategic early construction of inferences is relatively independent of the time available for reading the sentence. Furthermore, strategic orienting affects the computation of the inference during the reading of the sentence, not merely at a postcontext reactivation stage. It is, therefore, likely that the facilitation of the probe reflects activation of the inference shortly after the context sentence and remains active through the reader's encounter of the first word of the next sentence.

\section{GENERAL DISCUSSION}

The main findings of this study revealed that the drawing of predictive inferences during reading can be speeded up by means of a goal involving active anticipation of outcomes of the events described in sentences. As a summary of the results, Figure 1 shows the activation scores - that is, the differences between the control context and the predicting context for probe inferential targets and nonpredictable targets. Activation scores obtained in nonorienting conditions of closely related experiments (i.e., same materials, same temporal parameters, comparable participant samples; Calvo, 2000; Calvo et al.,
1999) have been added for comparison and to help determine how strategic orienting shortens the time needed to draw predictive inferences. The shortening of the time course by strategic orienting conditions is implied by the fact that in the prior studies inference activation was not detected until as late as 1,050 msec after the context under nonorienting conditions, whereas in the present strategic orienting conditions inferences were detected as early as 50 and 550 msec after the context.

Prior research in which the temporal parameters of stimulus presentation (i.e., rate of context word presentation and context-probe SOA) were controlled has generally revealed that predictive inferences are activated with some delay, which extends to about $1 \mathrm{sec}$ (e.g., Calvo et al., 1999; Fincher-Kiefer, 1995), and that this is also the case for related types of elaborative inferences (e.g., Long et al., 1994; Till et al., 1988). There are, nevertheless, some studies in which predictive inferences have been detected when the probe word appears 250 (Cook et al., 2001; Keefe \& McDaniel, 1993; McDaniel et al., 2001) to 500 (Cook et al., 2001; Klin, Guzmán, \& Levine, 1999; Murray et al., 1993; Peracchi \& O’Brien, 2004) msec after the end of the context under nonorienting conditions. This might lead us to think that, even with no strategic reading, predictive inferences can be drawn much earlier than $1 \mathrm{sec}$ following the inducing context. As was indicated in the introduction, however, in these studies self-paced presentation of the context sentences was used, which hampers control of the available time at the end of the context; therefore, the time course of the inference could not be determined with precision. This issue

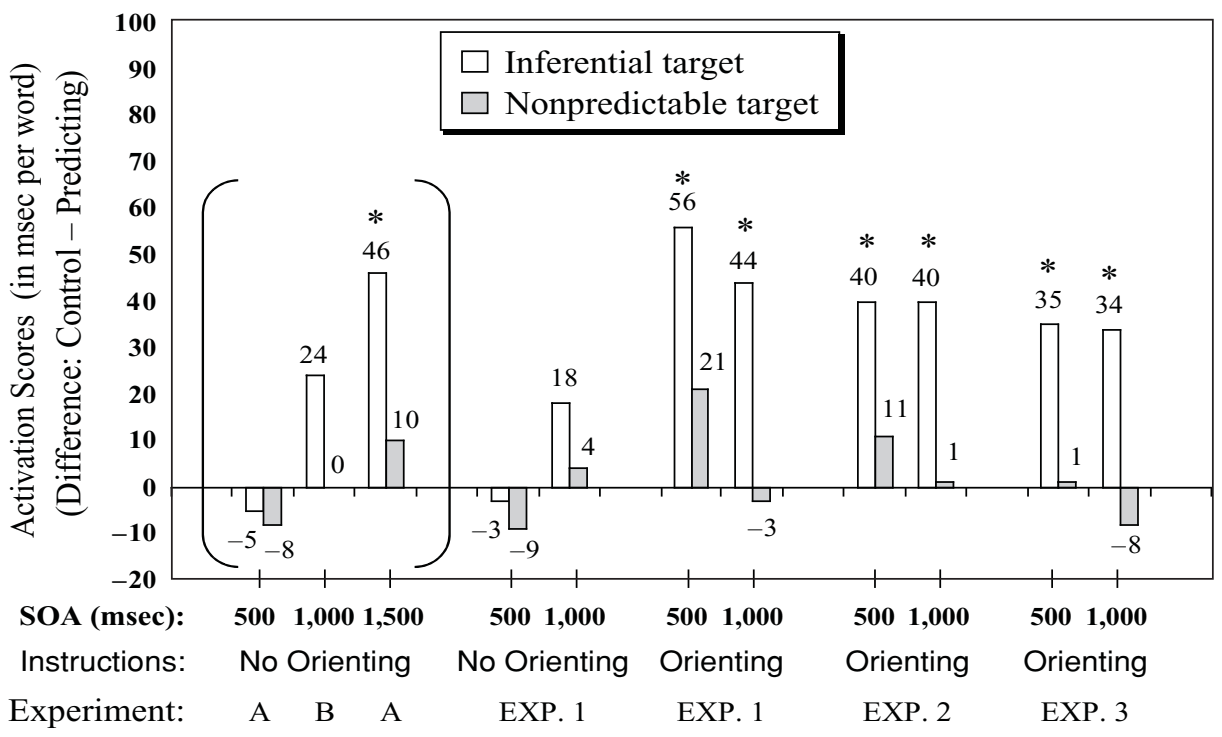

Figure 1. Activation scores (i.e., mean naming latency differences, in milliseconds per word, between control context and predicting context) for inferential and nonpredictable target words. Positive scores indicate facilitation in the predicting condition; negative scores show inhibition. Asterisks show significant differences between the predicting and the control context conditions. A, Experiments 1 (500-msec SOA) and 2 (1,500-msec SOA) of Calvo et al. (1999); B, Experiment 2A (1,000msec SOA) of Calvo (2000). 
can be better addressed by manipulating a fixed-pace presentation and the SOA. The present results converge with those of previous studies in which these manipulations were used, showing no inferential activation as early as $550 \mathrm{msec}$ after the end of the context (i.e., 1,000-msec SOA) in the nonorienting condition (Calvo \& Castillo, 1996, 1998, 2001), even when the fixed-pace presentation was significantly lengthened (i.e., mean word exposure of $628 \mathrm{msec}$ instead of $418 \mathrm{msec}$; Calvo et al., 1999). In contrast, in all the prior studies in which the temporal parameters were controlled, evidence of inferences made $800-1,050 \mathrm{msec}$ after the end of the context $(750 \mathrm{msec}$ in Fincher-Kiefer, 1995, 1996) was obtained using SOAs of 1,250-1,500 msec. The new finding of this study is that, with strategic orienting to predict the outcomes of described situations during reading, inferences were generated with practically no delay-that is, $50-550 \mathrm{msec}$ after the context.

This finding represents a challenge for the conceptualization of predictive inferences as elaborative processes that need considerable time to be performed. How can this significant reduction occur in the time it takes to draw inferences that are assumed to require complex cognitive machinery (e.g., multiple activation, selection, integration, situation model representation [see the C-I model]; Kintsch, 1998; Schmalhofer et al., 2002)? At first glance, it seems paradoxical (see Singer, Graesser, \& Trabasso, 1994, pp. 424-426) that, when reading is guided by specific strategic processing, predictive inferences may be computed as quickly as automatic, necessary inferences (e.g., bridging inferences, which can be drawn in under $500 \mathrm{msec}$; Magliano et al., 1993; Millis \& Graesser, 1994).

There are, however, some explanations for this effect. The significant reduction in the time taken to generate predictive inferences in the strategic orienting condition can be accounted for within the framework of the C-I model of comprehension (Kintsch, 1988, 1998; see Cook et al., 2001, and Schmalhofer et al., 2002). According to this model, during the construction phase multiple elaborations of the meanings of text segments are generated in parallel from the reader's prior knowledge (see also the resonance model proposed by Myers \& O'Brien, 1998, and the memory-based processing view developed by Gerrig \& McKoon, 1998). A selection process must then be performed, which enhances the activation of the context-relevant meanings and inhibits or suppresses all unnecessary activated meanings. The activated meanings are represented at three levels: surface text base, propositional meanings of the text structure, and referential or mental model of the situation described by the message. In a subsequent integration phase, converging activation for particular knowledge units from the three representation levels would create a state of interconnectivity. The multiple activation and specific selection processes of the construction phase are most relevant to the generation of inferences. In contrast, the state of interconnectivity of the integration phase is more relevant to the persistence of the previously activated inference in working memory and to its later storage in long-term memory. For predictive inferences, both activation and interconnectivity would be achieved at the situation model level, since they are not directly represented by the explicit text information but rather supported by the reader's prior knowledge.

In this conceptual framework, strategic orienting aimed at generating predictive inferences would speed up the construction processes of the situation model in several ways, thus shortening the time course of these inferences. First, the goal of reading to predict outcomes of the events described in the sentences would draw the reader's attention to the situation model representation rather than to the text-base (surface and propositional) levels. This would reallocate cognitive resources to the processes involved in mental modeling that are directly relevant to predictive inferences (see McDaniel et al., 2001). Second, the focus on strategic predicting would also reduce the allocation of cognitive resources to the construction of other types of inferences, such as explanations, associations, and the like, which take place during normal reading for comprehension (Trabasso \& Magliano, 1996; van den Broek et al., 2001). Third, strategic predicting instructions would make relevant prior world knowledge accessible earlier during sentence reading and, therefore, would facilitate the early construction of a mental model as a schema to be filled with the meanings of the sentence as it unfolds, rather than postponing it until sentence boundaries and wrap-up phases (Kintsch, 1988; Millis \& Graesser, 1994). Fourth, focusing on prediction of relevant outcomes of the events described in the sentence would produce a selection bias: It would enhance the activation of the most likely outcome rather than increase activation of all potential candidates. The most likely outcome would then become overrepresented and suppress other potentially predictable consequences. This would reduce the activation of multiple meanings in the construction phase, which would then shorten the processes of inhibition of irrelevant meanings in the selection stage. The four proposed functions of strategic predicting are assumed to converge in saving time in comparison with approaching the text with the more general goal of comprehension.

A related question is whether this increase in the efficiency of predictive inferencing is achieved at the expense of a reduction in the comprehension of explicit information in the text. Presumably, the predict strategy requires readers to reinstate and maintain in working memory relevant information from the prior context and determine how this information constrains their forward predictions (van den Broek, 1990). Accordingly, since this strategy demands cognitive resources, working memory resources are limited, and explicit comprehension processes also need resources, we might anticipate that strategic predicting would not come for free. This implies that comprehension of explicit information should have been reduced in the strategic inference condition in comparison with the nonorienting condition, but this was not the case. It might be thought that no such detrimental effect occurred because our passages involved low working-memory de- 
mands, given that they were short (21-word sentences), and because the assessment of comprehension took place immediately after reading. Against this interpretation, however, Magliano et al. (1999) also did not find negative effects with longer texts (of more than 10 sentences) and a long-term memory measure of comprehension (2 days after the reading phase). Accordingly, enhanced construction of implicit information can be present with no cost to extraction of explicit information.

In conclusion, the active use of strategic predictive inferencing can induce a flexible and efficient allocation of resources to both mental situation modeling and text-base processing. In contrast, reading with only the general purpose of comprehension may induce a minimal task-satisfaction strategy, leading one to perform only the automatic processes that are necessary to understand the message, or to perform elaborative processes with delay. Our findings have shown not only that the probability of predictive inferences can be enhanced during reading with the specific goal of predicting the outcomes of described events (Magliano et al., 1999) or with the goal of trying to imagine the situations described in the sentences (McDaniel et al., 2001), but also that the time course of these inferences is affected. Thus, even though resourcedemanding elaborative processes are involved, predictive inferences can be speeded up. Presumably, this occurs because of the facilitating effects of strategic orienting on the construction phase of mental situation modeling during reading comprehension (Kintsch, 1988, 1998).

\section{REFERENCES}

Alameda, J. R., \& Cuetos, F. (1995). Diccionario de frecuencias de las unidades lingüísticas del castellano [Dictionary of lexical frequencies of Spanish linguistic units]. Oviedo, Spain: Universidad de Oviedo.

Calvo, M. G. (2000). The time course of predictive inferences depends on contextual constraints. Language \& Cognitive Processes, 15, 293-319.

Calvo, M. G., \& Castillo, M. D. (1996). Predictive inferences occur on-line, but with delay: Convergence of naming and reading times. Discourse Processes, 22, 57-78.

Calvo, M. G., \& Castillo, M. D. (1998). Predictive inferences take time to develop. Psychological Research, 61, 249-260.

Calvo, M. G., \& Castillo, M. D. (2001). Bias in predictive inferences during reading. Discourse Processes, 32, 43-71.

Calvo, M. G., Castillo, M. D., \& Estevez, A. (1999). On-line predictive inferences in reading: Processing time during vs. after the priming context. Memory \& Cognition, 27, 834-843.

Calvo, M. G., Meseguer, E., \& Carreiras, M. (2001). Inferences about predictable events: Eye movements during reading. Psychological Research, 65, 158-169.

CAmpion, N., \& Rossi, J. P. (2001). Associative and causal constraints in the process of generating predictive inferences. Discourse Processes, 31, 263-291.

Cook, A., Limber, J. E., \& O'Brien, E. J. (2001). Situation-based context and the availability of predictive inferences. Journal of Memory \& Language, 44, 220-234.

DuFFY, S. A. (1986). Role of expectations in sentence integration. Journal of Experimental Psychology: Learning, Memory, \& Cognition, 12, 208-219.
FINCHER-KIEFER, R. (1995). Relative inhibition following the encoding of bridging and predictive inferences. Journal of Experimental Psychology: Learning, Memory, \& Cognition, 21, 981-995.

FinCHER-Kiefer, R. (1996). Encoding differences between bridging and predictive inferences. Discourse Processes, 22, 225-246.

Gerrig, R. J., \& McKoon, G. (1998). The readiness is all: The functionality of memory-based text processing. Discourse Processes, 26, 67-86.

Graesser, A. C., Singer, M., \& Trabasso, T. (1994). Constructing inferences during narrative text comprehension. Psychological Review, 101, 371-395.

Keefe, D. E., \& McDaniel, M. A. (1993). The time course and durability of predictive inferences. Journal of Memory \& Language, 32, 446-463.

Keenan, J. M., Golding, J. M., Potts, G. R., Jennings, T. M., \& Aman, C. J. (1990). Methodological issues in evaluating the occurrence of inferences. In A. C. Graesser \& G. H. Bower (Eds.), The psychology of learning and motivation: Vol. 25. Inferences and text comprehension (pp. 295-312). San Diego: Academic Press.

Kintsch, W. (1988). The role of knowledge in discourse comprehension: A construction-integration model. Psychological Review, 95, 163-182.

KInTSCH, W. (1998). Comprehension: A paradigm for cognition. New York: Cambridge University Press.

Kuin, C. M., Guzmán, A. E., \& Levine, W. H. (1999). Prevalence and persistence of predictive inferences. Journal of Memory \& Language, 40, 593-604.

Klin, C., Murray, J. D., Levine, W. H., \& Guzmán, A. E. (1999). Forward inferences: From activation to long-term memory. Discourse Processes, 27, 241-260.

Lea, R. B., Kayser, P. A., Mulligan, E. J., \& Myers, J. L. (2002) Do readers make inferences about conversational topics? Memory \& Cognition, 30, 945-957.

Long, D. L., OpPy, B. J., \& SeELy, M. R. (1994). Individual differences in the time course of inferential processing. Journal of Experimental Psychology: Learning, Memory, \& Cognition, 20, 1456-1470.

Magliano, J. P., Baggett, W. B., Johnson, B. K., \& Graesser, A. C. (1993). The time course of generating causal antecedent and causal consequence inferences. Discourse Processes, 16, 35-53.

Magliano, J. P., Trabasso, T., \& Graesser, A. C. (1999). Strategic processing during comprehension. Journal of Educational Psychology, 91, 615-629.

McDaniel, M. A., Schmalhofer, F., \& Keefe, D. E. (2001). What is minimal about predictive inferences? Psychonomic Bulletin \& Review, 8, 840-846.

McKoon, G., \& Ratcliff, R. (1986). Inferences about predictable events. Journal of Experimental Psychology: Learning, Memory, \& Cognition, 12, 82-91.

McKoon, G., \& Ratcliff, R. (1992). Inference during reading. Psychological Review, 99, 440-466.

Millis, K. K., \& Graesser, A. C. (1994). The time-course of constructing knowledge-based inferences for scientific texts. Journal of Memory \& Language, 33, 583-599.

Murray, J. D., Klin, C. M., \& Myers, J. (1993). Forward inferences in narrative text. Journal of Memory \& Language, 32, 464-473.

Myers, J. L., \& O’Brien, E. J. (1998). Accessing the discourse representation during reading. Discourse Processes, 26, 131-157.

Peracchi, K. A., \& O'Brien, E. J. (2004). Character profiles and the activation of predictive inferences. Memory \& Cognition, 32, 1044-1052.

Potts, G. R., Keenan, J. M., \& Golding, J. M. (1988). Assessing the occurrence of elaborative inference: Lexical decision versus naming. Journal of Memory \& Language, 27, 399-415.

Schmalhofer, F., McDaniel, M. A., \& Keefe, D. (2002). A unified model for predictive and bridging inferences. Discourse Processes, 33, 105-132.

Singer, M., Graesser, A. C., \& Trabasso, T. (1994). Minimal or global inference during reading. Journal of Memory \& Language, 33, 421-441. 
Till, R. E., Mross, E. F., \& Kintsch, W. (1988). Time course for associate and inference words in a discourse context. Memory \& Cognition, 16, 283-298.

Trabasso, T., \& Magliano, J. (1996). Conscious understanding during comprehension. Discourse Processes, 21, 255-287.

VAN DEN BRoEK, P. (1990). The causal inference maker: Towards a process model of inference generation in text comprehension. In D. A. Balota, G. B. Flores d'Arcais, \& K. Rayner (Eds.), Comprehension processes in reading (pp. 423-445). Hillsdale, NJ: Erlbaum.

VAN DEN Broek, P., Lorch, R. F., JR., Linderholm, T., \& GuSTAFSon, M. (2001). The effects of readers' goals on inference generation and memory for texts. Memory \& Cognition, 29, 1081-1087.
Weingartner, K. M., Guzmán, A. E., Levine, W. H., \& Kuin, C. M. (2003). When throwing a vase has multiple consequences: Minimal encoding of predictive inferences. Discourse Processes, 36, 131-146.

Whitney, P., Ritchie, B. G., \& Crane, R. S. (1992). The effect of foregrounding on readers' use of predictive inferences. Memory \& Cognition, 20, 424-432.

ZwaAn, R. A., \& Radvansky, G. A. (1998). Situation models in language comprehension and memory. Psychological Bulletin, 123, 162-185.

(Manuscript received April 28, 2004;

revision accepted for publication February 17, 2005.) 